\title{
Editorial
}

\section{Sally Dalhousie}

Sally Dalhousie is one of the co-convenors of the Pasifika Social Workers Interest Group and has been a member of the group since it began. Of Tongan descent, Sally is an Otago University graduate and loves to contribute to development initiatives at any level and in a variety of forums. Now living in Auckland, Sally works for West Fono Health Trust where she manages the community services.

\section{Introduction}

The journey of this publication commenced in 2004, when Dr Tracie Mafile'o sent out an email to Pacific members of the ANZASW to see if there was any interest in forming a Pacific Interest Group. The response affirmed that a Pacific Interest Group would be welcomed by members and the Pasifika Social Workers Interest Group was formed. Membership extended from Invercargill to Whangarei and contact was mainly maintained through an email network, with a few meetings held in Auckland.

By 2008, a few members of the group agreed to hold our Inaugural National Fono the day before the ANZASW's National Congress in April 2009. Twenty-four social and community workers from around New Zealand managed to travel to our humble gathering in support of Pacific social and community development. This editorial provides a record of the day where we 'shone the light on Pacific innovations' and decided to coordinate this edition of Tu Mau.

\section{Dancing with the stars}

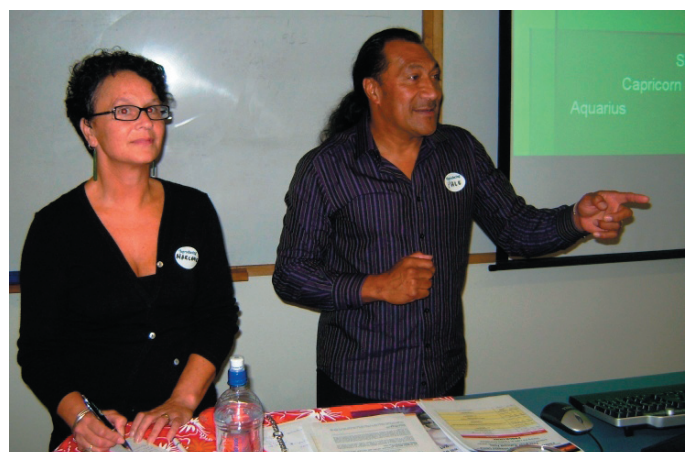

Pale Sauni and Marlane Welsh Sauni opened the presentations with the hilarious and insightful exercise known as 'dancing with the stars' ... In today's busy work schedule, we often minimise our own 'best interest' in pursuing the best outcomes for our clients, their families and the organisations that we work for. It's no wonder we feel 'crowded' by various influences when it comes to crisis and crossroads when we need to make decisions and provide advice.

This workshop gave us an opportunity to see ourselves through familiar things such as star signs, character traits and personality insights using star signs and a lot of humour: it was very good for the soul.

Participation and relevance were the key components of this workshop. It gave us the opportunity to take a fresh look at ourselves, perhaps for the first time in a long time. We also got to reflect on the communities which we serve as still holding the key to unlocking some of our very complex societal issues; we only need to be prepared to see ourselves as dancing with the stars. 
The Invisible Bridge: Fakaalofa, gifting and cultural reciprocity in social work education

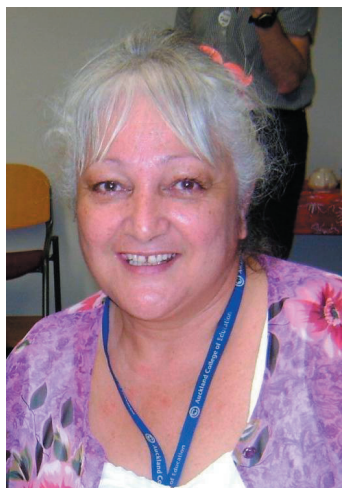

Insightful and provocative, Vaiolesi Passells shared her experiences as a Pasifika lecturer in a tertiary environment. Tensions arise when there is a disjuncture between the culture of an individual and their community, and the institution in which that individual is employed. From the framework of the Niue concept of fakaalofa ('to love', 'to greet', or 'to gift'), Vaiolesi outlined her experiences as a Niue social work lecturer in a western tertiary institution for social work education.

Vaiolesi outlined her experience of dynamics involved in being the sole person of colour in a social work educational programme. She discussed the notion of cultural reciprocity and the ways that she works as an 'invisible bridge' between the ethnic community and the institution. Vaiolesi's presentation illustrated some of the implications of working as an 'invisible bridge' by 'shining a light' on Pasifika innovations and the historical contributions from Pasifika communities.

\section{Kava Kumete Model}

'Fofola e fala kae 'ata ke fai ha lea.'

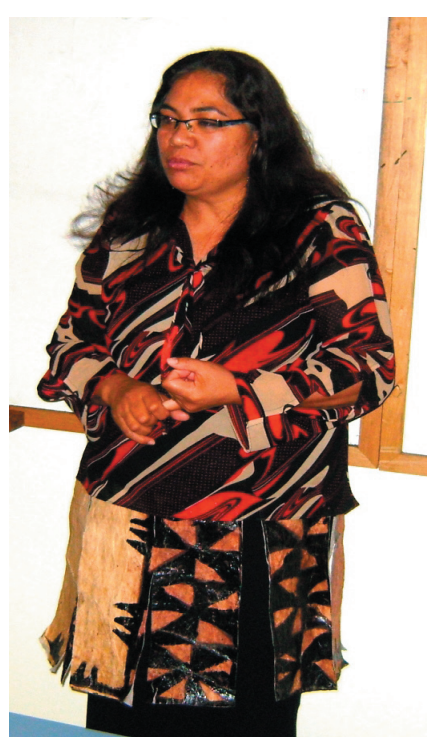

Unfold and spread out the mat and let us talk.

Reanter Kauvaka wowed the audience when she presented us with her 'kava kumete model', which outlines a Tongan cultural model of working with adult sex offenders from Pasifika backgrounds. The model has been developed out of Reanter's current work with child sex offenders at the SAFE Programme in Auckland through the Amanaki Pasifika programme.

The aim of the Amanaki Pasifika programme is to respond to the needs of our Pacific men and their families. Reanter acknowledges that a lack of understanding by professionals of language and the various Pasifika cultural protocols have been barriers to treatment, and developed this model as one way to overcome such barriers.

The working model is shaped by the 'Kumete Kava' concept from Tongan culture. 'Kumete kava' literally means 'kava bowl'. This model uses the kava bowl metaphor to strengthen treatment, and provides a shared cultural connection, changing the thinking, feeling and behaviours of male sex offenders from a Pasifika background.

\section{Pasifika Academic Success in Aotearoa}

Each school week some 80 students seek the services of the Pasifika Academic Student Support (PaSS) at the University of Auckland. Jayne Schwalger's role is to assist Pasifika students to work through students' issues, experiences, psycho-social needs and cultural perceptions that hinder their academic learning.

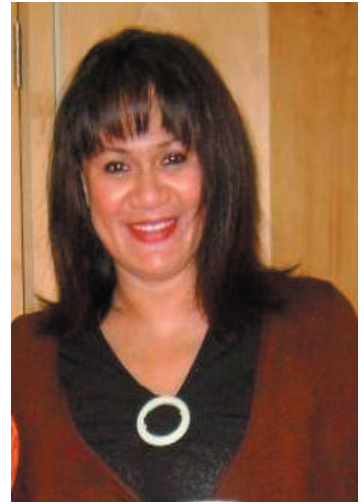


In observing and supporting Pasifika students at the Faculty, Jayne realised that there is a critical need to implement and use appropriate social work frameworks and Pasifika models of learning alongside academic pedagogies of learning, to assist our Pasifika students in raising their academic achievement.

Engaging in such critical discourse allows for greater awareness, leading to effective pathways for implementing such methods for Pasifika Academic Success in Aotearoa. Jayne shared the narratives and stories of Pasifika student academic success and answered questions on the successful outcomes and findings from an academic service based on social work interventions.

\section{Seeing past the hand}

Wrapping up the presentations, Pale and Marlane wove together all the presentations with eloquence and humour. They acknowledged that much of our practice is anchored in and informed by the logic of our qualifications, the clinical application of science, the success of proven case studies and the formalised best practice model that has worked in the past.

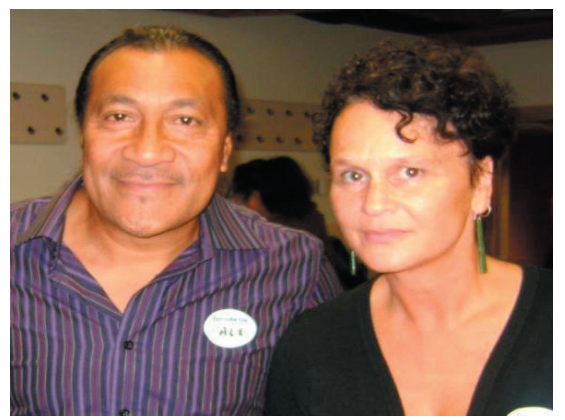

In Pasifika, there is a view that lagona or intuition, a sixth sense, a notion, a feeling and often an undescribed thought, is a valid and legitimate strength in pursuing complete interventions to resolve complex social health issues.

The challenges with applying this strength is its association with the unknown, the spiritual, the unquantifiable, the eerie touchy feely, the spooky even and the too 'non-text-book' approach. These factors can make it difficult to gain support for the practice of lagona, and as a consequence we may choose to remain within the safe boundaries of formal social work interventions and practice.

This workshop explored narratives where intervention is presented and analysed through the lens of lagona. Workshop attendees got to experience an approach which is real and allows us to be ourselves when moving in the world of Pasifika.

Following the presentations we held our business meeting where among other things we decided that we would use the Fono as a springboard to publishing this edition of Tu Mau.

The Pasifika Social Workers Interest Group is profoundly thankful to the contributors who submitted the articles for this edition of Tu Mau. Without action, our dreams cannot come to fruition - so we commend everyone for stepping up and responding to the challenge of collating your work into an article.

This edition of Tu Mau comprises of contributions from members and supporters of our group. Dr Patrick Vakaoti shares with us the research he completed in Fiji on 'Churchbased service provisions for street frequenting young men in Suva'. Tala Faletolu shares her research around 'Assumed voices in social work', while Vaiolesi Passels goes 'Navigating 


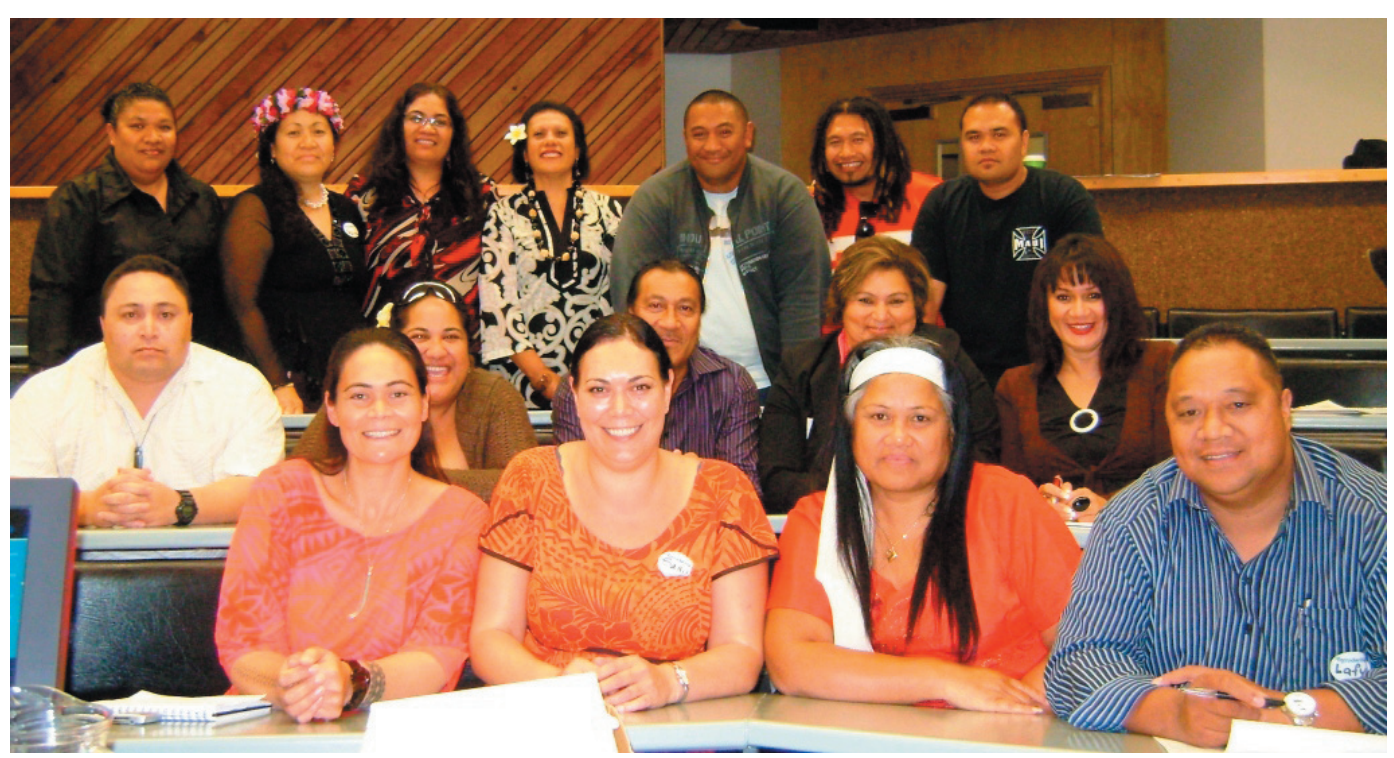

Present (at Business Meeting): (back row from left) Carolina Filipo, Vaine Williams-Joseph, Reanter Kauvaka, Atalana Treviranus, Michael Lalogafau, Bola Hausia, Sione Maka; (middle row from left) Shane Siataga, Diana Vao, Pale Sauni, Malia Lupe Lo, Jayne Schwalger; (front row from left) Niusulu Hellesoe, Sally Dalhousie, Loga Crichton, Lafulafu Peo (Marlane Welsh Sauni, photographer).

research currents'. Meanwhile aspiring Massey University students share their journey in applying the Le Laumei model to a collective project that focused on cultural protection through language preservation. We hope you enjoy this edition of Tu Mau which shines the light on Pacific innovations in social and community work within Aotearoa New Zealand, the Pacific and beyond.

To contact us, email: pasifikasw_intgrp@anzasw.org.nz 